ORIGINAL ARTICLE

\title{
ASSESSMENT OF HEALTH RELATED LIFE QUALITY IN TYPE 2 DIABETIC PATIENTS IN ZAGAZIG UNIVERSITY HOSPITALS
}

\author{
Mohamed A. Abdallah*, Emam Mohammed Esmayel, Mayada Mohamed Moussa \\ Internal Medicine Department, Faculty of Medicine - Zagazig University, Zagazig, Egypt
}

\section{Corresponding Author:}

Mohamed Ahmed Abdallah

Internal Medicine Department,

Faculty of Medicine - Zagazig

University, Zagazig, Egypt

Email:

dr_mohamed_abdalla2010@ya hoo.com

$\begin{array}{ll}\text { Submit Date } & 2019-03-18 \\ \text { Revise Date } & 2019-04-22 \\ \text { Accept Date } & 2019-04-25\end{array}$

\begin{abstract}
Background: The fourth leading cause of death is type 2 Diabetes Mellitus (DM). Attention to the QOL of the patient is increasing today rather than the longevity of the patient. Therefore, to prevent aggravation of metabolic disorders, the quality of life of diabetic patients should be maintained. There is a growing awareness that patient QOL and satisfaction with treatment have been improved after good glycemic control. The aim of this study was to assess health related quality of life in patients with type 2 diabetes attending Zagazig University hospital plus associations between HRQOL scores and some variables playing role in scenario of DM were also studied. Methods: A cross sectional study included 100 type 2 diabetic patients, They were subdivided according to glycemic control into 2 groups and 50 non-diabetic participants as control. This study was conducted in Internal Medicine department and diabetes outpatient clinic in Zagazig University hospital in period from July 2016 to July 2018. The QOL was measured using SF-36 questionnaire. Results: Our results revealed that there was highly significant difference regarding physical health component among groups of study $(\mathrm{p}<0.001)$. There was also highly significant difference regarding mental health component among groups of study $(\mathrm{p}<0.001)$. There was highly significant negative correlation between QOL components and age \& BMI \& duration of DM \& HBA1c and fasting blood sugar in diabetic patients $(\mathrm{p}<0.001)$. Conclusions: Type 2 diabetes mellitus in both the physical health and mental health domains is associated with a lower quality of life. Advanced age, obesity and poor glycemic control were factors related to lower quality of life in this study; therefore glycemic control is highly needed to improve the quality of life of diabetic patients.

Keywords: Quality of life; Glycemic control; HBA1c.
\end{abstract}

\section{INTRODUCTION}

The improvement in the quality of achievements in medicine alongside with the overall improvement of living conditions during the past decades increased the predominance of chronic disorders. Chronic diseases require medical treatment, progress slowly and can worsen the health of the patients and, thus, impair the overall health quality of life [1].

Over the past decades, the prevalence of DM in adults has increased. It should be noted that the number of people with DM will increase from 415 million in 2015 to 642 million in 2040, according to the International Diabetes Federation (IDF). IDF has recognized Egypt as the ninth leading country in the world for the number of type 2 diabetes patients and its prevalence was nearly tripled over the last 2 decades. Scientists now urge the global community to recognize DM as perhaps the single most important health challenge of the twenty first century [2].

The fourth leading cause of death is type 2 Diabetes Mellitus (DM). Attention to the 
QOL of the patient is increasing today rather than the longevity of the patient. Therefore, to prevent aggravation of metabolic disorders, the quality of life of diabetic patients should be maintained. There is a growing awareness that patient QOL and satisfaction with treatment have been improved after good glycemics [3] .

It is well established that in the developed and developing countries, the prevalence of diabetes has increased over the past four decades. This is due to the abundance of food, the resulting change in dietary habits and the lack of exercise [4].

Due to the natural aging process, the elderly are prone to various physical and mental problems and multiple diabetes - related problems make the aging process even more difficult and complicated [5].

QoL can be defined as a sense of wellbeing embracing the physical, psychological, social, and spiritual state. When we refer to QoL in patients with chronic diseases, we can define it as the overall assessment of the subject's life, which depends on both the subject's characteristics and external factors [6].

DM is known to be associated globally with increased morbidity and mortality. However, its impact on functional health status and well - being is still not well addressed, especially in developing countries where prevalence is rapidly increasing [7].

Although numerous articles and reviews on diabetes are written on an annual basis concerning epidemiology, complications, therapies, treatment comparisons and health strategies, literature on the quality of life of diabetes patients and how complications, comorbidities or different treatments actually affect them is limited [8].

QoL is often measured by self-reported instruments, including SF-36, which has two main physical and mental dimensions, each consisting of four sub-scales. Four subscales of physical function, limitation of physical activity, physical and general health comprise the physical dimension of quality of life. The psychological dimension includes vitality subscales, social function, mental role retardation and mental health [9].

Contrary to some quality of life tools that are limited to a specific group and are always criticized for such a limitation, the SF-36 is a general tool that can measure all important aspects of patient health. This tool can compare patients or patients with different conditions and diseases [10].

The aim of this study was to assess health related quality of life in patients $\mathrm{w}$ ith type 2 diabetes attending Zagazig University hospital plus associations between HRQOL scores and some variables playing role in scenario of DM were also studied.

\section{METHODS}

This study included 100 type 2 diabetic patients, they were subdivided according to glycemic control into 2 groups, 50 non-diabetic participants also included as a control.

Inclusion criteria: All patients were included comprehensively by Age $>30$ years and type 2 diabetes mellitus diagnosis with at least six months prior to the study. This study was a comparative cross sectional and conducted in Internal Medicine department and diabetes outpatient clinic in Zagazig University hospital in period from July 2016 to July 2018. A systematic random sample was done.

Exclusion criteria: Diabetic patients with overt complications (impaired vision, stage IV \& V CKD, loss superficial or deep sensation, charcot's joint, diabetic foot ulcer, limb amputation, stroke, MI), Type 1 diabetic patients, Pregnant women, Age $<30$ years

The HRQOL was assessed using the Arabic version of the Short-Form 36-item survey (SF-36). The SF-36 includes eight concepts of health: physical functioning, limitations of role due to physical health problems, limitations of role due to personal or emotional problems, body pain, emotional wellbeing, social functioning, energy / fatigue and general perceptions of health. Scores range from 0 to 100 , with higher values reflecting better quality of life associated with health.

Blood samples were obtained from all patients after 8 hours fasting. The poor 
glycemic control was characterized when HBA1c $\geq 7.5 \%$. On the other hand, good glycemic control is characterized when HBA1c $<7.5 \%$. The non - diabetic group has had random blood glucose tests to confirm that they do not suffer from diabetes mellitus to be included in the study.

\section{Ethical Considerations:}

The work has been carried out in accordance with The Code of Ethics of the World Medical Association (Declaration of Helsinki) for studies involving humans. Written informed consents were obtained from all patients. Approval by IRB research committee of Zagazig Faculty of Medicine was included

\section{Statistical analysis}

All data were coded, checked, entered and analyzed using the Windows Social Science Statistical Package (version 24.0; SPSS Inc., Chicago, IL, USA). Data were expressed and analyzed using descriptive statistics (mean \pm standard deviation). One - way variance analysis (ANOVA) test was performed to compare various parameters. between more than two groups. Pearson correlation coefficient was used to assess the association between quality of life component and other studied parameters. P-values were considered significant if $<0.05$

\section{RESULTS}

Our results showed matched data regarding frequency of age, gender, education and sociodemographic status among studied groups (Table 1). There was different data regarding complications, comorbidities, type of treatment and compliance among diabetic groups (Table 2)

Our results revealed that there was highly significant difference regarding physical health component (physical functioning, role limitation due to physical health, pain and general health) among groups of study ( $p$ $<0.001$ ) (Table 3). There was statistically high significant difference in values of physical health component in non-diabetic group compared to diabetic group (controlled \& uncontrolled) $(\mathrm{p}<0.001)$ and also statistically high significant difference among diabetic group (controlled \& uncontrolled) ( $\mathrm{p}<0.001)$.

There was also highly significant difference regarding mental health component (energy, role limitation due to emotional problem, emotional well-being and social functioning) among groups of study ( $p<0.001)$ (Table 4). There was statistically high significant difference in values of mental health component in non-diabetic group compared to diabetic group (controlled \& uncontrolled) $(\mathrm{p}<0.001)$ and also statistically high significant difference among diabetic group (controlled \& uncontrolled) $(\mathrm{p}<0.001)$.

Our results revealed that there was highly significant difference regarding BMI and waist circumference among groups of study ( $p$ $<0.001$ ) in which there was statistically significant difference in values of body mass index in non-diabetic group compared to diabetic group (controlled \& uncontrolled) while no statistically significant difference among diabetic group (controlled \& uncontrolled).

Our results revealed that there was highly significant negative correlation between physical health component (physical functioning, role limitation due to physical health, pain and general health) and age \& BMI $\&$ duration of DM \& HBA1c and fasting blood sugar in diabetic patients $(\mathrm{p}<0.001)$ (Table 5) \& (Figure 1).

There was also highly significant negative correlation between mental health component (energy, role limitation due to emotional problem, emotional well-being and social functioning) and age \& BMI \& duration of DM $\&$ HBA1c and fasting blood sugar in diabetic patients $(\mathrm{p}<0.001)$ (Table 6).

Also by univariate linear analysis, the statistical significant independent negative predictors to physical and mental health component were age, body mass index, duration of DM, HBA1c and fasting blood ( $\mathrm{p}$ $<0.001)$. 
Table (1): Frequency of distribution of socio-demographic and anthropometric data of all studied participants.

\begin{tabular}{|c|c|c|c|}
\hline Variables & $\begin{array}{l}\text { Uncontrolled } \\
\text { diabetics } \\
\begin{array}{l}(\mathrm{n}=50) \\
\mathrm{n}(\%)\end{array}\end{array}$ & $\begin{array}{l}\text { Controlled } \\
\text { diabetics }(\mathrm{n}=50) \\
\qquad \mathrm{n}(\%)\end{array}$ & $\begin{array}{l}\text { Non-diabetics } \\
\begin{array}{l}(\mathbf{n}=\mathbf{5 0}) \\
\mathbf{n}(\%)\end{array}\end{array}$ \\
\hline $\begin{array}{c}\text { Age (years) } \\
30-40 \\
41-50 \\
51-60 \\
\geq 61\end{array}$ & $\begin{array}{r}13(26 \%) \\
16(32 \%) \\
16(32 \%) \\
5(10 \%)\end{array}$ & $\begin{array}{r}13(26 \%) \\
15(30 \%) \\
17(34 \%) \\
5(10 \%)\end{array}$ & $\begin{aligned} & 14(28 \%) \\
& 14(28 \%) \\
& 15(30 \%) \\
& 7(14 \%)\end{aligned}$ \\
\hline $\begin{array}{l}\text { Gender } \\
\text { Male } \\
\text { Female }\end{array}$ & $\begin{array}{l}27(54 \%) \\
23(46 \%)\end{array}$ & $\begin{array}{l}29(58 \%) \\
21(42 \%)\end{array}$ & $\begin{array}{l}23(46 \%) \\
27(54 \%)\end{array}$ \\
\hline $\begin{array}{l}\text { Marital status } \\
\text { Married } \\
\text { Not married }\end{array}$ & $\begin{array}{r}45(90 \%) \\
5(10 \%)\end{array}$ & $\begin{array}{r}46(92 \%) \\
4(8 \%)\end{array}$ & $\begin{array}{c}46(92 \%) \\
4(8 \%)\end{array}$ \\
\hline $\begin{array}{l}\text { Residence } \\
\text { Urban } \\
\text { Rural }\end{array}$ & $\begin{array}{l}19(38 \%) \\
31(62 \%)\end{array}$ & $\begin{array}{l}23(46 \%) \\
27(54 \%)\end{array}$ & $\begin{array}{l}21(42 \%) \\
29(58 \%)\end{array}$ \\
\hline $\begin{array}{l}\text { Education } \\
\text { Yes } \\
\text { No }\end{array}$ & $\begin{array}{r}41(82 \%) \\
9(18 \%)\end{array}$ & $\begin{array}{r}46(92 \%) \\
4(8 \%)\end{array}$ & $\begin{array}{l}40(80 \%) \\
10(20 \%)\end{array}$ \\
\hline $\begin{array}{l}\text { Smoking } \\
\text { Yes } \\
\text { No }\end{array}$ & $\begin{array}{l}20(40 \%) \\
30(60 \%)\end{array}$ & $\begin{array}{l}17(34 \%) \\
33(66 \%)\end{array}$ & $\begin{array}{c}10(20 \%) \\
40(80 \%)\end{array}$ \\
\hline $\begin{array}{l}\text { BMI }(\mathrm{Kg} / \mathrm{m} 2) \\
\text { 18.5: } 24.9 \\
\text { 25: } 29.9 \\
\geq 30\end{array}$ & $\begin{array}{r}6(12 \%) \\
31(62 \%) \\
13(26 \%)\end{array}$ & $\begin{array}{r}10(20 \%) \\
31(62 \%) \\
9(18 \%)\end{array}$ & $\begin{array}{c}17(34 \%) \\
33(66 \%) \\
0(0 \%)\end{array}$ \\
\hline $\begin{array}{l}\text { Waist circumference }(\mathrm{cm}) \\
\quad \leq 80 \\
\quad 81: 89 \\
\geq 90\end{array}$ & $\begin{array}{c}1(2 \%) \\
14(28 \%) \\
35(70 \%)\end{array}$ & $\begin{array}{r}3(6 \%) \\
13(26 \%) \\
34(68 \%)\end{array}$ & $\begin{array}{r}3(6 \%) \\
27(54 \%) \\
20(40 \%)\end{array}$ \\
\hline
\end{tabular}


Table (2): Frequency of distribution of clinical data of diabetic patients

\begin{tabular}{|c|c|c|}
\hline Variable & $\begin{array}{l}\text { Uncontrolled diabetics } \\
(\mathbf{n = 5 0 )} \mathbf{n}(\%)\end{array}$ & $\begin{array}{l}\text { Controlled diabetics }(\mathrm{n}=50) \\
\mathrm{n}(\%)\end{array}$ \\
\hline $\begin{array}{l}\text { Duration of DM } \\
\text { (years) } \\
\quad \leq 5 \\
6-10 \\
11-15 \\
16-19 \\
\geq 20\end{array}$ & $\begin{array}{r}12(24 \%) \\
11(22 \%) \\
11(22 \%) \\
9(18 \%) \\
7(14 \%)\end{array}$ & $\begin{array}{r}9(18 \%) \\
15(30 \%) \\
15(30 \%) \\
5(10 \%) \\
6(12 \%)\end{array}$ \\
\hline $\begin{array}{l}\text { Comorbidities } \\
\text { No } \\
\text { Hypertension } \\
\text { Liver diseases } \\
\text { Chest diseases }\end{array}$ & $\begin{array}{c}14(28 \%) \\
36(72 \%) \\
7(14 \%) \\
1(2 \%)\end{array}$ & $\begin{array}{r}26(52 \%) \\
23(46 \%) \\
4(8 \%) \\
1(2 \%)\end{array}$ \\
\hline $\begin{array}{l}\text { Complications } \\
\text { No } \\
\text { Neuropathy } \\
\text { Retinopathy } \\
\text { Nephropathy }\end{array}$ & $\begin{array}{l}7(14 \%) \\
43(86 \%) \\
12(24 \%) \\
19(38 \%)\end{array}$ & $\begin{array}{r}27(54 \%) \\
23(46 \%) \\
7(14 \%) \\
5(10 \%)\end{array}$ \\
\hline $\begin{array}{l}\text { Treatment } \\
\text { Oral } \\
\text { Insulin } \\
\text { Both }\end{array}$ & $\begin{array}{c}28(56 \%) \\
20(40 \%) \\
2(4 \%)\end{array}$ & $\begin{array}{r}46(92 \%) \\
1(2 \%) \\
3(6 \%)\end{array}$ \\
\hline $\begin{array}{l}\text { Compliance to } \\
\text { treatment } \\
\text { Yes } \\
\text { No }\end{array}$ & $\begin{array}{l}29(58 \%) \\
21(42 \%)\end{array}$ & $\begin{array}{r}50(100 \%) \\
0(0 \%)\end{array}$ \\
\hline $\begin{array}{l}\text { Blood glucose home } \\
\text { monitoring } \\
\text { Yes } \\
\text { No }\end{array}$ & $\begin{array}{r}8(16 \%) \\
42(84 \%)\end{array}$ & $\begin{array}{l}40(80 \%) \\
10(20 \%)\end{array}$ \\
\hline $\begin{array}{l}\text { Blood glucose } \\
\text { checking } \\
\text { Feeling ill } \\
\text { Every } 3 \text { months } \\
\text { Weekly }\end{array}$ & $\begin{array}{c}47(94 \%) \\
3(6 \%) \\
0(0 \%)\end{array}$ & $\begin{array}{r}6(12 \%) \\
36(72 \%) \\
8(16 \%)\end{array}$ \\
\hline
\end{tabular}


Table (3): Comparison of physical health component of SF-36 of all studied participants.

\begin{tabular}{|c|c|c|c|c|c|}
\hline Variable & $\begin{array}{c}\text { Uncontrolled } \\
\text { diabetics } \\
(\mathrm{n}=50)\end{array}$ & $\begin{array}{c}\text { Controlled } \\
\text { diabetics } \\
(\mathrm{n}=50)\end{array}$ & $\begin{array}{c}\text { Non- } \\
\text { diabetics } \\
(\mathrm{n}=50)\end{array}$ & $\mathrm{F}$ & \\
\hline $\begin{array}{c}\text { Physical functioning } \\
\text { Role limitation due to } \\
\text { physical health }\end{array}$ & $53.5 \pm 8.16$ & $77.6 \pm 5.27$ & $93.2 \pm 5.02$ & 501.54 & $0.001^{*}$ \\
\hline Pain & $64.65 \pm 8.6$ & $73.25 \pm 6.85$ & $80.85 \pm 3.9$ & 72.08 & $0.001^{*}$ \\
\hline General health & $51.2 \pm 7.32$ & $76.6 \pm 8.11$ & $78.4 \pm 5.92$ & 224.59 & $0.001^{*}$ \\
\hline
\end{tabular}

Table (4): Comparison of mental health component of SF-36 of all studied participants.

\begin{tabular}{|c|c|c|c|c|c|}
\hline Variable & $\begin{array}{c}\text { Uncontrolled } \\
\text { diabetics } \\
(\mathrm{n}=50)\end{array}$ & $\begin{array}{c}\text { Controlled } \\
\text { diabetics } \\
(\mathrm{n}=50)\end{array}$ & $\begin{array}{c}\text { Non- } \\
\text { diabetics } \\
(\mathrm{n}=50)\end{array}$ & $\mathrm{F}$ & \\
\hline Energy & $54.1 \pm 7.6$ & $73.1 \pm 4.6$ & $86.5 \pm 5.8$ & 351.5 & $0.001^{*}$ \\
\hline Emotional well being & $72 \pm 4.35$ & $80.48 \pm 4.6$ & $87.84 \pm 3.2$ & 185.9 & $0.001^{*}$ \\
\hline Social functioning & $63.25 \pm 7.74$ & $67 \pm 9$ & $76.7 \pm 8.37$ & 34.42 & $0.001^{*}$ \\
\hline $\begin{array}{c}\text { Role limitation due to } \\
\text { emotional problems }\end{array}$ & $61.9 \pm 11.67$ & $69.9 \pm 10.1$ & $85.97 \pm 16.6$ & 43.54 & $0.001^{*}$ \\
\hline
\end{tabular}


Table (5): Pearson correlation coefficient between physical health component (physical functioning, role limitation due to physical health, pain, general health) and some studied variables in diabetic patients.

\begin{tabular}{|c|c|c|c|c|c|c|c|c|}
\hline & \multicolumn{2}{|c|}{ Physical functioning } & \multicolumn{2}{|c|}{$\begin{array}{l}\text { Role limitation due } \\
\text { to physical health }\end{array}$} & \multicolumn{2}{|c|}{ pain } & \multicolumn{2}{|c|}{ General health } \\
\hline Variables & $\mathbf{R}$ & $\mathbf{P}$ & $\mathbf{r}$ & $\mathbf{P}$ & $\mathbf{r}$ & $\mathbf{P}$ & $\mathbf{r}$ & $\mathbf{P}$ \\
\hline Age & -0.376 & $<0.001 *$ & -0.461 & $<0.001 *$ & -0.672 & $<0.001 *$ & -0.442 & $<0.001 *$ \\
\hline Body mass index & -0.340 & $<0.001^{*}$ & -0.352 & $<0.001 *$ & -0.411 & $<0.001 *$ & -0.339 & $<0.001 *$ \\
\hline $\begin{array}{l}\text { Waist } \\
\text { circumference }\end{array}$ & -0.126 & 0.106 & -0.116 & 0.250 & -0.127 & 0.207 & -0.131 & 0.194 \\
\hline Duration of DM & -0.422 & $<0.001 *$ & -0.501 & $<0.001 *$ & -0.616 & $<0.001 *$ & -0.439 & $<0.001 *$ \\
\hline HBA1c & -0.935 & $<0.001^{*}$ & -0.862 & $<0.001 *$ & -0.751 & $<0.001 *$ & -0.892 & $<0.001^{*}$ \\
\hline Fasting blood sugar & -0.929 & $<0.001^{*}$ & -0.834 & $<0.001^{*}$ & -0.675 & $<0.001^{*}$ & -0.915 & $<0.001 *$ \\
\hline
\end{tabular}

Table (6): Pearson correlation coefficient between mental health component (role limitation due to emotional problems, social functioning, energy, emotional well-being) and some studied variables in diabetic patients.

\begin{tabular}{|c|c|c|c|c|c|c|c|c|}
\hline \multirow[b]{2}{*}{ Variables } & \multicolumn{2}{|c|}{$\begin{array}{l}\text { Role limitation due to } \\
\text { emotional problems }\end{array}$} & \multicolumn{2}{|c|}{ Social functioning } & \multicolumn{2}{|c|}{ Energy } & \multicolumn{2}{|c|}{$\begin{array}{l}\text { Emotional well- } \\
\text { being }\end{array}$} \\
\hline & $\mathbf{r}$ & $\mathbf{P}$ & $\mathbf{r}$ & $\mathbf{P}$ & $\mathbf{r}$ & $\mathbf{P}$ & $\mathbf{r}$ & $\mathbf{P}$ \\
\hline Age & -0.374 & $<0.001 *$ & -0.721 & $<0.001 *$ & -0.400 & $<0.001 *$ & -0.554 & $<0.001 *$ \\
\hline Body mass index & -0.335 & $<0.001^{*}$ & -0.395 & $<0.001 *$ & -0.293 & $<0.003^{*}$ & -0.354 & $<0.001 *$ \\
\hline Waist circumference & -0.098 & 0.331 & -0.105 & 0.300 & -0.104 & 0.301 & -0.141 & 0.161 \\
\hline Duration of DM & -0.411 & $<0.001^{*}$ & -0.638 & $<0.001 *$ & -0.438 & $<0.001 *$ & -0.544 & $<0.001 *$ \\
\hline HBA1c & -0.586 & $<0.001^{*}$ & -0.549 & $<0.001 *$ & -0.928 & $<0.001 *$ & -0.845 & $<0.001 *$ \\
\hline Fasting blood sugar & -0.519 & $<0.001 *$ & -0.453 & $<0.001 *$ & -0.911 & $<0.001 *$ & -0.818 & $<0.001 *$ \\
\hline
\end{tabular}




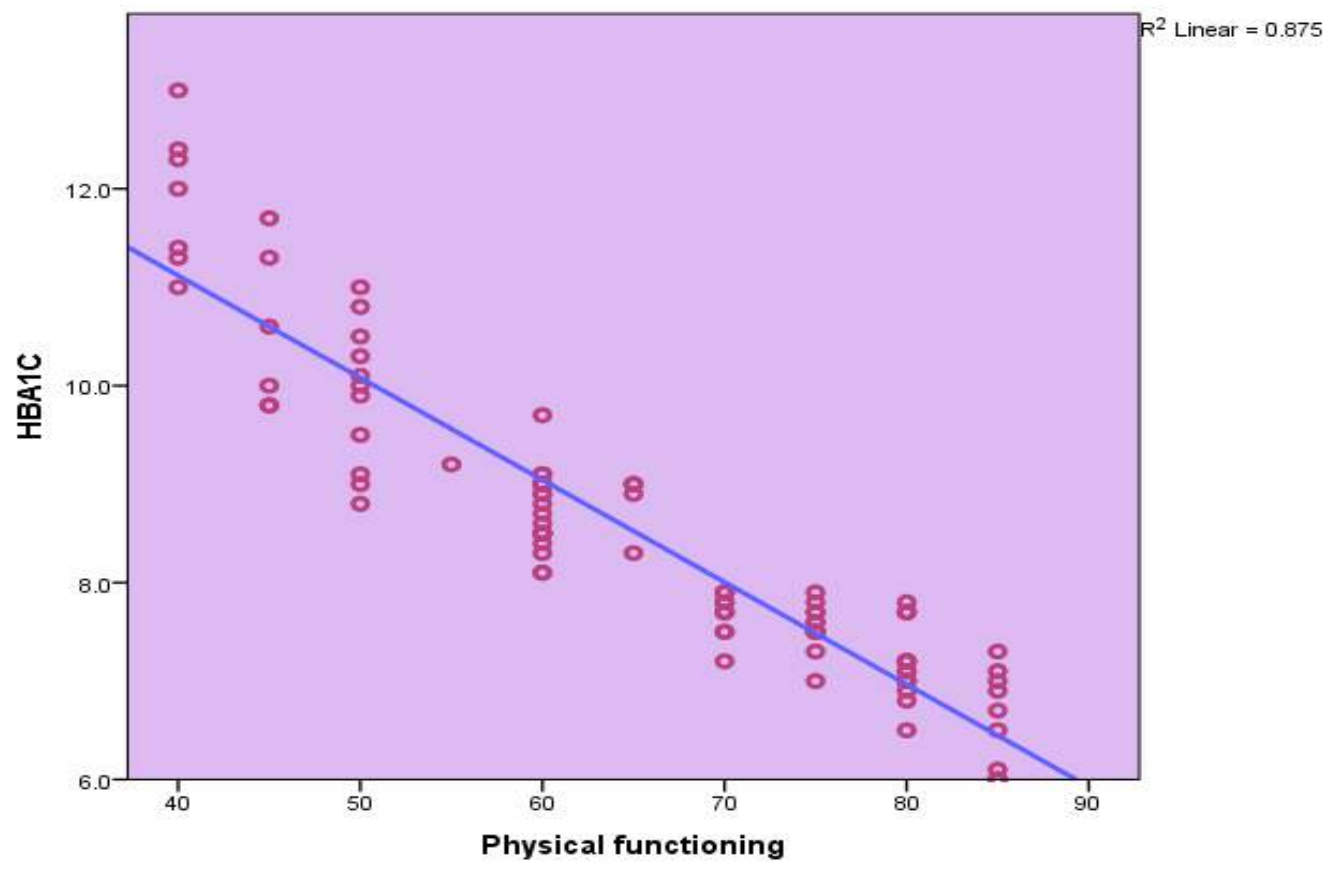

Figure (1): showed the negative correlation between physical functioning and HBA1c

\section{DISCUSSION}

Our results revealed that there was highly significant difference regarding physical health component (physical functioning, role limitation due to physical health, pain and general health) among groups of study ( $\mathrm{p}$ $<0.001)$. there was statistically high significant difference in values of physical health component in non-diabetic group compared to diabetic group (controlled \& uncontrolled) $(\mathrm{p}<0.001)$ and also statistically high significant difference among diabetic group (controlled \& uncontrolled) $(\mathrm{p}<0.001)$.

There was also highly significant difference regarding mental health component (energy, role limitation due to emotional problem, emotional well-being and social functioning) among groups of study ( $\mathrm{p}<0.001$ ). There was statistically high significant difference in values of mental health component in non-diabetic group compared to diabetic group (controlled \& uncontrolled) $(\mathrm{p}<0.001)$ and also statistically high significant difference among diabetic group (controlled \& uncontrolled $)(p<0.001)$.

These results were consistent with Abd El Latif et al. who found patients with type 2 diabetes in Suez Canal University Hospitals in Ismailia city had low QoL in physical health domain, psychological health and environmental domains through World Health Organization Quality of Life Questionnaire [11]. This could be explained as there was a higher rate of complications in type 2 diabetic patients that affected the physical function. Physical function limitations can have a negative impact on quality of life, especially due to vision difficulties, peripheral neuropathy or heart disease.

Sengül et al. investigate the effect of duration of diabetes and glycemic regulation on the quality of life (QOL) in type 2 diabetic turkish patients using the SF-36 and found that the scores for QOL parameters of role limitations-physical, bodily pain, physical functioning, general health, energy and role limitations-emotional were significantly lower than those of the healthy controls $(\mathrm{p}<0.05$ for each) [12].

Sengül et al. also found that there was no statistically significant difference $(p>0.05)$ when comparing the QOL scores of cases with HbA1c levels of about 7\% and 7-10\%. They also found a non-significant difference in the 
physical functioning, body pain, general health, vitality and social functioning scores of cases with HbA1c levels of $\leq 7 \%$ and those with levels of $\geq 10 \% \quad(p>0.05)$. On the other hand, they found a significant difference in role limitations-physical and role limitationsemotional scores between the two groups $(\mathrm{p}=0.016$ and $\mathrm{p}=0.019$, respectively). When comparing the QOL scores of cases with HbA1c levels of $7-10 \%$ and $>10 \%$, they detected a significant difference between physical limitations $(\mathrm{p}=0.034)$, physical pain $(p=0.037)$, energy $(p=0.043)$ and emotional limitations $(p=0.033)$. However, in these two groups $(p>0.05)$ there was no such significant difference between other QOL parameter scores [12].

Kamarul et al. compared quality of life based on SF-36 between two different groups of type 2 diabetes mellitus patients with glycaemic control: patients with $\mathrm{HbA1c}$ at or below $7.5 \%$ and patients above $7.5 \%$. and found that patients with poor glycaemic control group (HbA1c level > 7.5\%) consistently scored lower than those with a HbAlc level $\leq$ $7.5 \%$. However, none was statistically significant. The SF-36 scores were also lower in these patients than the Malaysian population's SF-36 standards[13].

On other hand, Thommasen and Zhang found that paradoxically, improved blood sugar control was associated with poor physical functioning, physical role, physical pain, emotional and social functioning scores [14].

Nerenz et al also reported that tight glycemic control (as measured by glycosylated hemoglobin) was associated with lower SF-36 dimensional ratings [15]. Lloyd et al also reported that average levels of blood glucose were inversely associated with some of the isolatedSF-36 domains, including vitality [16]. Lower HRQOL scores associated with improved blood sugar control may reflect morbidity inherent in this patient population's need to keep blood sugars within normal levels.

Our results revealed that there was highly significant difference regarding BMI and waist circumference among groups of study ( $p$
$<0.001)$ in which there was statistically significant difference in values of body mass index in non-diabetic group compared to diabetic group (controlled \& uncontrolled) while no statistically significant difference among diabetic group (controlled \& uncontrolled).

Also this finding agreed with Abd Elaziz et al. who found that the mean body mass index was higher in the patient group $31.5 \pm 5.8$ compared to $29.3 \pm 5.7$ in the control group and the difference was statistically highly significant.. The prevalence of overweight among patient group was $33.3 \%$ while obesity was $56 \%$. [17].

Our results revealed that there was highly significant negative correlation between quality of health component and age \& BMI \& duration of DM \& HBA1c and fasting blood sugar in diabetic patients $(\mathrm{p}<0.001)$.

As regards to the relation between quality of life and HbA1c, Abd El Latif et al found that there was a negative dependence between HbA1c and the physical health domain and that there was no relationship of statistical significance with other domains [11].

This finding contradicted Genga et al. which found that the quality of $\mathrm{HbAlc}$ glycemic control did not affect HRQoL and its domains among diabetic patients of type 2 [18].

Abd El Latif et al revealed a significant negative relationship between BMI and physical and psychological health domains with respect to the relationship between quality of life domains and body mass index [11]. These findings disagreed with Kazemi-Galougahi et al., who found that the relationship between BMI and QOL domains was not significant [19].

Regarding the association between age and HRQOL, Mamaghanian et al. found that in young and old patients, the lowest and highest mean HRQOL scores were obtained respectively [20].

As the age increases, it also increases the risk of developing other diseases and diabetes complications. The quality of life of Type 2 
diabetes patients is therefore expected to decline as their age increases.

On the other hand, In Riyadh, Saudi Arabia, Ibrahim et al. describe the health related quality of life in type 2 diabetes patients and found that no statistically significant associations were found between health related quality of life and age scores [21].

\section{CONCLUSION}

Type 2 diabetes mellitus in both the physical health and mental health domains is associated with a lower quality of life. Advanced age, obesity and poor glycemic control were factors related to lower quality of life in this study, therefore glycemic control is highly needed to improve the quality of life of diabetic patients

\section{ACKNOWLEDGMENTS}

We thank Mohamed Mohamed Hassan, Department of Internal Medicine, Zagazig University, Egypt for his cooperation in the study.

\section{Declaration of interest}

The authors report no conflicts of interest. The authors alone are responsible for the content and writing of the paper.

Funding information: None declared REFERENCES

[1] Sionti V, Papageorgiou g, Peschos D, Charalambous G, Kotrotsiou e, Christodoulides $\mathrm{P}$ et al., Quality of life in patients with type 2 diabetes mellitus: a cross-sectional study. IJPHM 2019.

[2] International Diabetes Federation (2017). "IDF Diabetes Atlas 7th Edn.", available at: www.diabetesatlas.org

[3] Amelia R, Lelo A, Lindarto D and Mutiara E. Quality of life and glycemic profile of type 2 diabetes mellitus patients of Indonesian: a descriptive study. IOP Conf. Series: Earth and Environmental Science 2018;125 (1) .

[4] Da Rocha Fernandes J, Ogurtsova K, Linnenkamp U, Guariguata L, Seuring T, Zhang P et al.,. IDF Diabetes Atlas estimates of 2014 global health expenditures on diabetes. Diabetes Res Clin Pract 2016; 117: 48-54

[5] Atif M, Saleem Q, Babar Z and Scahill S. Association between the Vicious Cycle of Diabetes-Associated Complications and
Glycemic Control among the Elderly: A Systematic Review. Medicina 2018; 54: 73.

[6] Zurita-Cruz J, Manuel-Apolinar L, Arellano-Flores M, Gutierrez-Gonzalez A, Najera-Ahumada A and Cisneros-González N. Health and quality of life outcomes impairment of quality of life in type 2 diabetes mellitus: a cross-sectional study. Health and Quality of Life Outcomes. 2018; 16: 94.

[7] Reba K, Argaw Z, Walle B and Gutema H. Healthrelated quality of life of patients with diagnosed type 2 diabetes in Felege Hiwot Referral Hospital, North West Ethiopia: a crosssectional study. BMC Res Notes 2018; 11: 544 .

[8] Trikkalinou A, Papazafiropoulou A, Melidonis A. Diabetes type 2 and quality of life. World J Diabetes 2017; 8(4): 120-171.

[9] Mokhtari Z, Gheshlagh RG, Kurdi A. Health-related quality of life in Iranian patients with type 2 diabetes: An updated metaanalysis, Diabetes \& Metab Syndr 2019; 13(1): 402-407.

[10] Reba K, Argaw Z, Walle B and Gutema H. Health related quality of life of patients with diagnosed type 2 diabetes in Felege Hiwot Referral Hospital, North West Ethiopia:a crosssectional study. BMC Res Notes 2018; 11:544

[11] Abd El Latif FI, Abd El Wahid HA, Amina Ahmed Mohamed AA, Farg HK. Physical and psychological health domains of quality of life in type 2 diabetic patients in relation to clinical factors of diabetes mellitus in Egypt. Int Res $\mathbf{J}$ Med Med Sci,2016; 4(1): 7-16.

[12] Müge S, Erdogan M, Sokmen N, Canataroglu A. Evaluation of Life Quality Functions in Patients with Type 2 Diabetes Mellitus. Turkish Journal of Endocrinology and Metabolism, 2008; 12: 68-72.

[13] Kamarul Imran M, Ismail A, Naing L, Wan Mohamad W. Type 2 diabetes mellitus patients with poor glycaemic control have lower quality of life scores as measured by the Short Form36. Singapore Med J, 2010; 51(2): 158

[14] Harvey $T$ and William Z. Health-related quality of life and type 2 diabetes: A study of people living in the Bella Coola Valley. BC MEDICAL JOURNAL, 2006; 48 ( 6): 272278.

[15] Nerenz DR, Repasky DP, Whitehouse FW, et al. Ongoing assessment of health status in 
patients with diabetes mellitus. Med Care 1992; 30 (5 suppl):MS112-124.

[16] Lloyd A, Sawyer W, Hopkinson P. Impact of long-term complications on quality of life in patients with type 2 diabetes not using insulin. Value Health 2001; 4:392- 400.

[17] Abd Elaziz K, Nour-Eldin F, Momen M, Damaty S. Assessment of health related quality of life among diabetics' patients in Al Gharbia Governorate, Egypt using COOP/WONCA charts. The Egypt J Commun Med 2014; 32(3):47-58

[18] Genga E.K, Otieno C.F, Ogola E.N. Assessment of the Perceived Quality of Life of non insulin Dependent Diabetic patients attending the Diabetes Clinic in Kenyatta
National Hospital. IOSR J Pharm 2014; 4 (3); 15-21.

[19] Kazemi GMH, Navidi GH, Eftekhar AH, Mahmoudi H. Quality of life in type 2 diabetic patients and related effective factors. Indian $\mathbf{J}$ Med Sci. 2012; 66 (9): 230-237.

[20] Mamaghanian A, Shamshirgaran SM, Aiminisani N, Aliasgarzadeh A. Clinicoepidemiological factors of health related quality of life among people with type 2 diabetes. World J Diabetes 2017; 8 (8): 407413

[21] AL-Aboudi I, Hassali M, Shafie A, Hassan A and Alrasheedy A. A cross-sectional assessment of health-related quality of life among 2 diabetes patients in Riyadh, Saudi Arabia. SAGE Open Medicine, 2015; 3.

To Cite This Article: Abdallah MA, Esmayel EM, Moussa MM.Assessment of Health Related Life Quality in Type 2 Diabetic Patients in Zagazig University Hospitals.ZUMJ 2019;25(6);790-800. DOi: 10.21608/zumj.2019.10752.11200 . 